\title{
A population based study to assess the nutritional status of adolescents of Hajipur village of Katihar district, Bihar, India
}

\author{
Shahin Rahman ${ }^{1}$, Mohd Haroon Khan ${ }^{1}$, Mohammad Makhmoor Alam², \\ Khushboo Juneja ${ }^{1}$, Seema Kumari ${ }^{3}$
}

\begin{abstract}
${ }^{1}$ Department of Community Medicine, S.H.K.M. Govt Medical College, Nalhar (Mewat), Haryana, India
${ }^{2}$ Department of Opthalmology, S.H.K.M., Govt Medical College, Nalhar (Mewat), Haryana, India

${ }^{3}$ Department of Community Medicine, Indira Gandhi Institute of Medical Sciences, Patna, Bihar, India
\end{abstract}

Received: 05 November 2015

Accepted: 11 December 2015

\author{
*Correspondence: \\ Dr. Shahin Rahman, \\ E-mail: shahin_rahman2008@yahoo.com
}

Copyright: () the author(s), publisher and licensee Medip Academy. This is an open-access article distributed under the terms of the Creative Commons Attribution Non-Commercial License, which permits unrestricted non-commercial use, distribution, and reproduction in any medium, provided the original work is properly cited.

\begin{abstract}
Background: Adolescents are the future generation of any country. They constitute 22.8 percent of the total population in India. The main nutritional problems affecting adolescent population include undernutrition and iron deficiency anaemia besides other factors. The objective of the study was to assess the nutritional status among adolescents.

Methods: A Community based cross sectional descriptive study. Rural field practice area of Department of Community Medicine, Katihar Medical College, Katihar, Bihar. Participants: 400 adolescents (213 boys and 187 girls). Systematic random sampling technique was used. Data collected was entered in Microsoft Office Excel and analysed by using SPSS version 20.0.

Results: Among 400 adolescents, 253(63.25\%) adolescents had Body Mass Index less than normal (18.5kg/m2) value. Prevalence of undernutition in the adolescent girls was high (36.75\%) and prevalence of overweight in adolescent boys and girls is $1.25 \%$ and $1 \%$ respectively. Prevalence of chronic energy deficiency (CED) based on BMI (gradeI, II, III) in adolescent girls are $21.25 \%, 7.25 \%, 8.25 \%$ respectivey. And CED grade I, II, III in adolescent boys are $21.75 \%, 1.5 \%, 3.25 \%$ respectively. Moderate malnutrition is higher in girls (7.25\%) than in boys (1.5\%) and severe malnutrition is also higher in girls $(8.25 \%)$ than in boys $(3.25 \%)$.

Conclusions: If the adolescents are well nourished, they can make optimal use of their skills, talents and energies and would be healthy and responsible citizens.
\end{abstract}

Keywords: Adolescents, Nutritional Status, Body mass index

\section{INTRODUCTION}

Undernutrition is a major public health problem of the adolescents. In certain cultures, from infancy onwards including adolescence, girls are at particularly high risk because of gender discrimination. Poor nutritional status during adolescence is an important determinant of health outcomes. Short stature in adolescents resulting from chronic undernutrition is associated with reduced lean body mass and deficiencies in muscular strength and working capacity. ${ }^{1}$ The adolescents were categorized into various grade based on BMI according to WHO
International Standard. ${ }^{2,3,4}$ That is, Grade 3 thinness (BMI $<16 \mathrm{~kg} / \mathrm{m} 2$ ), Grade 2 thinness (BMI 16-16.9 kg/m2), Grade 1 thinness (BMI 17-18.49 kg/m2), Normal (BMI 18.5-24.99 kg/m2), Overweight (BMI 25-29.99 kg/m2) and Obese (BMI >30 kg/m2). ${ }^{5}$ Obesity can be seen as the first wave of a defined Cluster of noncommunicable diseases called "New World Syndrome" creating an enormous socioeconomic and public health burden in poorer countries. The health risks include cardiovascular diseases, diabetes, osteoarthritis, gallbladder disease and some sex hormone-sensitive cancers. ${ }^{6}$ Obesity is considered to be a global epidemic, has spread its major 
roots in our children and adolescents. Overweight children have double chances to become obese adult than normal children. ${ }^{7}$ Overweight and obesity during adolescent period are associated with risk factors for obesity-related diseases in adulthood. ${ }^{8}$ In several countries of Asia, for instance, poorer nutritional status of women becomes apparent during adolescence, with a delay in maturation. ${ }^{9}$ The low nutritional status of adolescents is a matter of a serious concern. One third of boys and girls have chronic Energy Malnutrition in India. ${ }^{10}$ About 59 percent boys and 37 percent girls are stunted in India. ${ }^{11}$ National Nutrition Monitoring Bureau $(\mathrm{NNMB})^{12}$ also reported that undernutrition decreased from 78 percent in $10-13$ years to 66 percent in $14-17$ years.

\section{METHODS}

The present population based, cross sectional, descriptive study was undertaken among adolescents (10-19 Years) in Hajipur village of Katihar district, Bihar. The population of the Hazipur village is about 10000. The numbers of houses were approximately 1800. Data will be collected from adolescents (10-19 Years) of Hajipur village in Katihar district, Bihar. The study was undertaken during January to December (2012).

\section{Sample Size}

On the basis of this prevalence of undernutrition among adolescents the sample size of the present study has been calculated by adopting the formula:

$$
\mathrm{n}=\frac{\mathrm{Z}^{2} \alpha / 2 \times \mathrm{PQ}}{\sum^{2}}
$$

Where,

$\mathrm{P}=$ Prevalence rate of the disease $=50 \%=0.50$

$\mathrm{Q}=1-\mathrm{P},=0.50$

$\alpha=$ level of Significance (type 1 error)

$\mathrm{Z}^{2} \alpha / 2=4$

$\sum=$ Allowable error $10 \%$ of $\mathrm{P}$

Then $\mathrm{n}=\underline{4 \times 0.50 \times 0.50}=400$

$$
.0025
$$

Hence the required study sample size is 400 adolescents (10-19 Years).

\section{Sampling technique}

Houses that are having at least one adolescent or more will be numbered serially. Then the houses were selected by systematic random sampling technique.

\section{Inclusion Criteria for sampling}

The study will be conducted on adolescents who were of both the gender (Adolescent boys and girls), willing to participate in the study and apparently healthy on general physical examination.

\section{Exclusion Criteria for sampling}

The study exclude adolescents who were above 19 years of age and below 10 years of age group, not willing to participate in the study, with chronic illness or receiving long term allopathic or indigenous drugs and with history of any severe illness within the past 2 weeks for which they required hospitalization.

\section{Data Collection Method}

Written informed consent was taken from the head of the household of adolescents who were below eighteen years, and direct written informed consent was taken from girls who were eighteen years and above. After establishing good rapport with the family, detailed information about socio-demographic characteristics/profile (age, education and occupation of parents, socio-economic status of the family, types of family, family size), dietary intake and contributory factors in relation with health were recorded in the predesigned and pretested questionnaire. Subject suffering from severe morbidity symptoms like URTI, ENT, Eye problems were referred to Katihar Medical College, Katihar for proper treatment.

\section{Clinical Examination}

A female attendant was present during examination of girls. Anthropometric measurement i.e., height and weight of each subject will be taken according to the standard procedure. Nutritional status of study subjects will be assessed by using various parameters viz. weight for age, height for age, weight for height, stunting and thinness (BMI for age) will be calculated as per the National Centre for Health and Statistic (NCHS).

\section{Height}

Height in centimeters was taken with the help of height measuring rod. The height was recorded to the nearest 1 centimeter.

\section{Weight}

A bathroom scale was used. It was calibrated against known weights regularly. The zero error was checked form and removed if present, every day. The clothes of the girls were not removed because adequate privacy was not available. So girls were asked to wear light weighted cloths. Their weight was recorded to the nearest 500 gms.

\section{Body Mass Index}

Body Mass Index (BMI) is defined as weight in $\mathrm{kg}$ divided by height in square meter $\left(\mathrm{kg} / \mathrm{m}^{2}\right)$. Chronic energy deficiency in adults can be measured by body mass index.

\section{Data analysis}


Data collected was entered in Microsoft Office Excel and analysed by using SPSS version 20.0. Dependent variable frequencies, percentage, mean, range and proportion were calculated. Chi-square test and Yate's correction were used for statistical analysis. The differences were considered as significant at a $\mathrm{p}$ value of $<0.05$.

\section{RESULTS}

Among 400 adolescents (213 boys and 187 girls) the largest number of adolescents $41.5 \%$ belong to $10-14$ years of age group followed by $32.5 \%$ and $26 \%$ in the age group 15-17 years, and 18-19 years respectively. Out of them $53.25 \%$ and $46.75 \%$ are boys and girls respectively. And $24.75 \%$ boys and $16.75 \%$ girls are in age group of $10-14$ years followed by $17.75 \%$ boys, $14.75 \%$ girls and $10.75 \%$ boys, $15.25 \%$ girls in age group $15-17$ years and 18-19 years respectively. The mean age of dolescent boys and girls is $14.5 \pm \mathrm{SD} 2.89$ years and $15.37 \pm \mathrm{SD} 2.82$ years respectively (Table 1). As can be seen from Table 2 mean weight, mean height and mean Body Mass Index in adolescent boys are $39.37 \pm$ SD6. $55 \mathrm{~kg}, 1.43 \pm$ SD. $1 \mathrm{~m}$ and $19.21 \pm \mathrm{SD} 2$. $14 \mathrm{~kg} / \mathrm{m}^{2}$ respectively and mean weight, mean height and mean Body Mass Index of adolescent girls are $36.67 \mathrm{~kg} \pm$ SD6. $3 \mathrm{~kg}, 1.43 \pm \mathrm{SD}$. $1 \mathrm{~m}$ and 17.76 $\pm 1.91 \mathrm{~kg} / \mathrm{m}^{2}$ respectively. It is clearly seen from Figure 1 prevalence of undernutition in the adolescent girls was high $147(36.75 \%)$ and prevalence of overweight in adolescent boys and girls is $5(1.25 \%)$ and $4(1 \%)$ respectively $\left(\chi^{2}\right.$ value $\left.=36.786, \mathrm{df}=2, \mathrm{p}<0.0001\right)$. It appears from Table 3 that $63.25 \%$ adolescents are underweight $(\mathrm{BMI}<18.5)$ and prevalence of chronic energy deficiency (CED) based on BMI (grade I, II, III) in adolescent girls are 21.25\%, 7.25\%, 8.25\% respectively and CED grade I, II, III in adolescent boys are $21.75 \%, 1.5 \%, 3.25 \%$ respectively. Moderate malnutrition is higher in girls $(7.25 \%)$ than in boys
$(1.5 \%)$ and severe malnutrition is also higher in girls $(8.25 \%)$ than in boys $(3.25 \%)$.

Table 1: Distribution of adolescent boys and girls according to age group.

\begin{tabular}{|lllll|}
\hline $\begin{array}{l}\text { Variables } \\
\text { (in Years) }\end{array}$ & Description & $\begin{array}{l}\text { Boys } \\
(\%)\end{array}$ & $\begin{array}{l}\text { Girls } \\
(\%)\end{array}$ & $\begin{array}{l}\text { Total } \\
(\%)\end{array}$ \\
\hline \multirow{2}{*}{$10-14$} & Early & 99 & 67 & 166 \\
& adolescent & $(24.75)$ & $(16.75)$ & $(41.5)$ \\
\hline \multirow{2}{*}{$15-17$} & Mid & 71 & 59 & 130 \\
& adolescent & $(17.75)$ & $(14.75)$ & $(32.5)$ \\
\hline \multirow{2}{*}{$18-19$} & Late & 43 & 61 & 104 \\
& adolescent & $(10.75)$ & $(15.25)$ & $(26)$ \\
\hline \multirow{2}{*}{ Total } & & 213 & 187 & 400 \\
& & $(53.25)$ & $(46.75)$ & $(100)$ \\
\hline
\end{tabular}

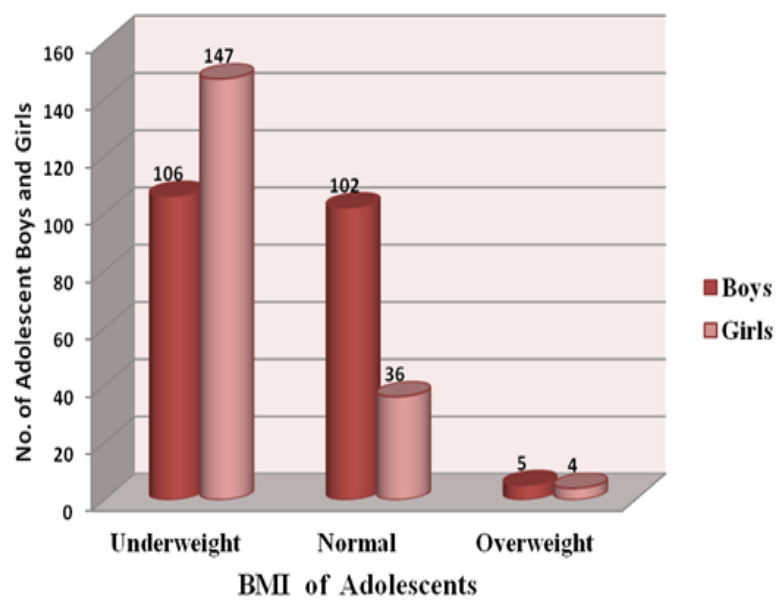

Figure 1: Nutritional status of adolescent boys and girls according to body mass index (BMI).

Table 2: Mean weight, mean height and mean BMI of adolescent boys and girls.

\begin{tabular}{|lllllll|}
\hline Mean & Boys & $\begin{array}{l}\text { Standard } \\
\text { Deviation }( \pm \text { SD) }\end{array}$ & $\begin{array}{l}\text { Standard Error } \\
( \pm \text { SE) }\end{array}$ & Girls & $\begin{array}{l}\text { Standard } \\
\text { Deviation }( \pm \text { SD })\end{array}$ & $\begin{array}{l}\text { Standard } \\
\text { Error }( \pm \text { SE) }\end{array}$ \\
\hline Mean Weight $(\mathrm{kg})$ & 39.37 & 6.55 & 0.49 & 36.67 & 6.3 & 0.46 \\
\hline Mean Height $(\mathrm{m})$ & 1.43 & 0.1 & 0.01 & 1.43 & 0.1 & 0.01 \\
\hline Mean BMI $\left(\mathrm{kg} / \mathrm{m}^{2}\right)$ & 19.21 & 2.14 & 0.15 & 17.76 & 1.91 & 0.14 \\
\hline
\end{tabular}

Table 3: Malnutrition (chronic energy deficiency) in adolescent boys and girls.

\begin{tabular}{|ll|ll|l|}
\hline $\begin{array}{l}\text { Chronic Energy Deficiency } \\
(\text { CED) }\end{array}$ & $\begin{array}{l}\text { BMI } \\
\left(\mathrm{kg} / \mathrm{m}^{2}\right) \text { of Adolescents }\end{array}$ & Boys $(\%)$ & Girls $(\%)$ & Total $(\%)$ \\
\hline Grade I & Mild thinness $(17.00-18.49)$ & $87(21.75)$ & $85(21.25)$ & $172(43)$ \\
\hline Grade II & Moderate thinness $(16.00-16.99)$ & $6(1.5)$ & $29(7.25)$ & $35(7.25)$ \\
\hline Grade III & Severe thinness $(<16.00)$ & $13(3.25)$ & $33(8.25)$ & $4611.5)$ \\
\hline & Total & $106(26.5)$ & $147(36.75)$ & $253(63.25)$ \\
\hline
\end{tabular}

It is clearly seen from Figure 2 that 105 (26.25\%), 80 $(20 \%)$ and $68(17 \%)$ of adolescents in age group 10-14 years, 15-17 years and 18-19 years are underweight $\left(<18.5 \mathrm{~kg} / \mathrm{m}^{2}\right)$ respectively. $5(1.25 \%) 3(0.75 \%)$ and 1 
(0.25\%) of adolescents in age group 10-14 years, 15-17 years and 18-19 years are overweight $\left(>25 \mathrm{~kg} / \mathrm{m}^{2}\right)$ respectively. Prevalence of under nutrition decreases with increase age group and also observed that the finding of the study lead us to conclude that a significant relation does not exist between the subjects BMI with age group $\left(\chi^{2}\right.$ value $\left.=1.486 \mathrm{df}=4, \mathrm{p}>0.05\right)$.

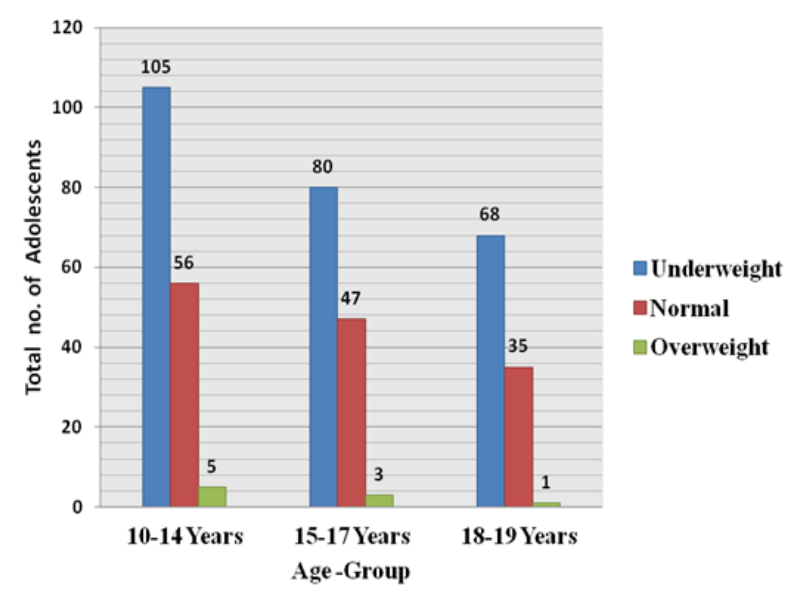

Figure 2: Prevalence of Undernutrition According to Age group.

\section{DISCUSSION}

Similar to our study Dambhare et al. ${ }^{13}$ found that $68.97 \%$ were boys and $31.03 \%$ were girls. Mean age of the adolescents was $13.16 \pm 1.99$. Patil et al. ${ }^{14}$ stated that 5.3 $\%$ of adolescent girls were in age group 11-14 years, $32.7 \%$ in the age group $15-17$ years, $61.9 \%$ were in the age group of 17-19 years. The mean age adolescent girls were 16.9 years. Kumar observed in a study that 69 $(28.2 \%)$ were in early adolescent (10-13 years), 73 $(29.8 \%)$ were in mid adolescent (14-15 years) and 103 (42\%) were in late adolescent (16-19 years) and the mean age of the girls was 15.2. ${ }^{15}$ Prajapati et al reported that mean weight and height of the adolescents were $45.34 \mathrm{~kg}$ $(2 \mathrm{SD}=11.08)$ and $147.35 \mathrm{~cm}(2 \mathrm{SD}=9.99)$ respectively. Mean BMI was $22.71 \mathrm{~kg} / \mathrm{m}^{2}$ (2 SD=35.06). ${ }^{16}$ Gupta et al observed that mean height and mean weight of the girls was found $151.012+13.36 \mathrm{~cm}, \quad 40.69+12.60 \mathrm{~kg}$ respectively. ${ }^{17}$ Jain et al (2010) reported that prevalence of overweight and obesity was found to be $19.7 \%$ and $5.3 \%$ in girls and $18.36 \%$ and $10.82 \%$ in boys. Obesity was found to be significantly associated with high intake of Junk foods $(\mathrm{p}<0.05)$, binge eating, high calorie intake $(\mathrm{p}<0.05)$, lower physical activity $(\mathrm{p}<0.05)$ and prolonged TV watching $(<0.05) .{ }^{18}$ Wasnik et al. reported that according to WHO reference standards, $2.9 \%$ was found to be overweight and none of the girls was found to be obese. As per new guidelines by the Government of India $5.8 \%$ was found to be overweight (BMI >23.5 $\left.\mathrm{kg} / \mathrm{m}^{2}\right) .{ }^{19}$ Dambhare et al. found in a study, that $48.3 \%$ of the adolescents were normal and $51.7 \%$ were malnourished. ${ }^{13}$ Chowdhry et al reported that BMI less than $19 \mathrm{~kg} / \mathrm{m}^{2}$ to be as high as $69 \%$ in rural Varanasi. ${ }^{20}$
Sethi and Kapoor reported that prevalence of obesity was $7.8 \%$ and $13.4 \%$ from Delhi. ${ }^{21}$ Dey et al stated that and only $3 \%$ were at risk of overweight while none of them was obese. ${ }^{22}$ Jayatissa et al. reported that prevalence of over weight was $4.0 \% .{ }^{23}$ Choudhary et al. reported that $68.52 \%$ of the adolescents had BMI less than 18.5 in rural area of Varanasi. ${ }^{24}$ Shahabuddin et al. observed that $59.0 \%$ adolescent girls were thin. ${ }^{25}$ This higher figure of thinness in their study may be attributed to poor socioeconomic conditions of rural Bangladesh. Shivaramakrishna et al. found in a study that $73.3 \%$ girls were under-nourished $(\mathrm{BMI}<18.5)$ and prevalence of chronic energy deficiency based on BMI (grade I, II and III) were $23.0 \%, 28.3 \%$, and $22.2 \%$ respectively. ${ }^{26}$ Garba et al. conducted a study and found that the severe malnutrition was higher in girls $(23.8 \%)$ than in boys $(22.3 \%)$, while moderate malnutrition was higher in boys $(93.1 \%)$ than in girls $(86.7 \%) .{ }^{27}$ Dey et al. stated that and only $3 \%$ were at risk of overweight while none of them was obese. $40 \%$ of the adolescents were undernourished and $0.5 \%$ had BMI greater than 2SD. Severe malnutrition was found to present in $27 \%$ boys and $29 \%$ girls. $^{22}$ Wasnik et al observed that $56.4 \%$ girls were under-nourished (BMI $<18.5 \mathrm{~kg} / \mathrm{m}^{2}$ ). Girls suffering from chronic energy deficiency grade I, II and III were $25.2 \%, 15.2 \%$ and $16 \%$ respectively. ${ }^{19}$ Maiti et al observed in a study that only $28.2 \%$ girls were normal and $25.7 \%, 30.4 \%, 13.7 \%$, and $1.9 \%$ of adolescent girls were suffering from CED Grade I, Grade II, Grade III and Grade IV respectively. ${ }^{28}$ Alam et al observed that the prevalence of undernutition in the adolescent girls was high; $9 \%$ were severely thin, $16 \%$ moderately thin and $0.3 \%$ obese. The prevalence of thinness was higher in early and late adolescence (it was $31 \%$ at the age of 13 years, fell to $20 \%$ at the age of 15 years, and increased to $33 \%$ at the age of 18 years). Of the pre-pubertal girls, $58 \%$ were thin, suggesting that under nutrition had delayed puberty. ${ }^{29}$ Kumar found in a study that prevalence of stunting was $47(19.2 \%)$ and wasting was $69(28.2 \%)$. Prevalence of under nutrition were common among the girls in the late adolescent group, Hindus, those who lived joint family, low monthly income and with the family size more than $7 .{ }^{15}$ Maliye et al documented in a study that $57 \%$ of the adolescent girls were thin and $43 \%$ were normal. None of them were overweight or obese. The prevalence of thinness was significantly higher $67.6 \%$ in early adolescence than in late adolescence $55.4 \% .^{30}$ Bisai, et al observed that rate of underweight was more among late adolescents than early adolescents, because it was found that this late adolescent age group was more health conscious related to weight. ${ }^{31}$

\section{CONCLUSION}

Poor nutritional status during adolescence is an important determinant of health outcomes. Short stature in adolescents resulting from chronic undernutrition is associated with reduced lean body mass and deficiencies in muscular strength and working capacity. 
From infancy onwards adolescent girls are at high risk of undernutrition because of gender discrimination. Due to poorer nutritional status, heavy workload lead to chronic deprivation of food particularly during the period of growth and development leads to chronic malnutrition and short stature of girls.

\section{ACKNOWLEDGMENTS}

I would like to express my profound gratitude to all the participants for their co-operation and for their immense faith they reposed in me.

\section{Funding: No funding sources}

Conflict of interest: None declared

Ethical approval: The study was approved by the Institutional Ethics Committee

\section{REFERENCES}

1. Physical status: The use and interpretation of anthropometry. Technical report series. Geneva; World Health Organization. 1995:854.

2. The International Classification of underweight, overweight and obesity according to BMI Source: Adapted from WHO, 1995, WHO, 2000 and WHO 2004.

3. Cole TJ, Bellizzi MC, Flegal KM, Dietz WH. Establishing a Standard definition for child overweight and obesity worldwide: International survey. BMJ. 2000;320(7244):1240-3.

4. Cole TJ, Flegal KM, Nicholls D, Jackson AA. Body mass index cut offs to define thinness in children and adolescents: international survey. BMJ. 2007;335(7612):1948.

5. World Health Organization. Nutritional status of adolescent girls and women of Reproductive age. Report of Regional consultation, Geneva, World Health Organization. SEA / NUT. 1998;141:3.

6. World Health Organization. Obesity: preventing and managing the global epidemic. Technical, Geneva: WHO. 2000;894.

7. International Life Sciences Institutes, preventing childhood obesity is a Current Research Focus: Initiatives cooperate to share Information and Stem Epidemic. The PAN Report: Physical Activity and Nutrition, USA, International Life Science Institute. 2000;2:5.

8. Physical status: The use and interpretation of anthropometry. Technical report series. Geneva; World Health Organization; 1995.Report No.:854.

9. Waslien CI, Stewart LK; Nutrition of the Asian adolescent girl Asia Pac J Public Health. 1994;7(1):31-3.

10. Lal Sunder, Adarsh, Pankaj. Text Book of community Medicine, Preventive and Social Medicine, 3rd edition, 2011, CBS Publishers and Distributors Pvt. Ltd. 154 -160.
11. Kishore JJ. Kishore's National Health Programs of India. Century Publications, New Delhi. 2011;9:176-9.

12. National Nutrition Monitoring Bureau. Diet and nutritional status of rural population NNMB Technical Report No. 21, National Institute of Nutrition, Indian Council of Medical Research Hyderabad. 2002.

13. Dambhare DG, Bharambe MS, Mehendale AM, Garg BS. Nutritional Status and Morbidity among School going Adolescents in Wardha, a Peri-Urban area. Online J. Health Allied Scs. 2010;9(2):1-3.

14. Patil SN, Wasnik V, Wadke R. Health Problems Amongst Adolescent Girls in rural areas of Ratnagiri District of Maharashtra, India. 2009;3(5):1784-90.

15. Kumar TA. Nutritional Status of Adolescent Girls in Rural Tamilnadu. Nat J Res Com Med. 2012;1(1):160.

16. Prajapati M, Bala DV, Tiwari H. A study of nutritional status and high risk behaviour of adolescents in Ahmedabad: A Cross Sectional Study Healthline. 2011;2,(1):21-26.

17. Gupta N, Kohar G. Pervasiveness of Anaemia In Adolescent Girls of Low Socio-Economic Group of The District of Kurukshetra (Haryana), The Internet Journal of Nutrition and welfare. 2009;7(1).

18. Jain S, Pant B, Chopra H, Tiwari R. Obesity Among Adolescents of Affluent Public schools in Meerut. Indian Journal of Public Health. 2010;54,I-3.

19. Wasnik V, Rao BS, Rao D. A Study of the Health Status of Early adolescent Girls residing in Social Welfare Hostels in Vizianagaram district of Andhra Pradesh State, India International Journal of Collaborative Research on Internal Medicine \& Public Health 2012;4(1):72-82.

20. Choudhury S, Mishra CP, Shukla KP. Nutritional status of adolescent girl in rural area of Varanasi. Indian J. Preventive and Social Medicine. 2003;34(1):53-61.

21. Sethi M, Kapoor P. Obesity. New Delhi: Voluntary Health Association of India. 2003.

22. Dey I, Biswas R, Ray K, Bhattacherjee S, Chakraborty M, Pal PP. Nutritional status of school going adolescents in a rural block of Darjeeling, West Bengal India. 2011;2(3):75-7.

23. Jayatissa R, Piyasena Cl, Warnakulasuriya I, Mahamithawa A. Overweight, thinness and stunting among adolescent schoolgirls in Sri Lanka: prevalence and associated factors. Department of Nutrition, Medical research institute, Colombo. 1997.

24. Choudhury P, Vir S. Prevention and strategies for control of iron deficiency anaemia. 1st ed. Nutrition in children: Developing Country Concerns. 1994;492-524.

25. Shahabuddin AK, Talukdar K, Talukdar MK, Hassan M, Seal A, Rahman Q, et al. Adolescent 
Nutrition in a rural community in Bangladesh. Indian J Pediatr. 2000;67(2):93-8.

26. Shivaramakrishna HR, Deepa AV, Sarithareddy M. Nutritional Status of Adolescent Girls in Rural Area of Kolar District-A Cross-Sectional Study Al Ameen J. Med. Sci. 2011;4,(3):243-6.

27. Garba CMG, Mbofung CMF. Relationship between Malnutrition and Parasitic Infection among School Children in the Adamawa Region of Cameroon. Pakistan Journal of Nutrition. 2010;9,(11):1094-9.

28. Maiti S, Chattterjee K, Ali KM, Ghosh D, Paul S. Assessment of nutritional status of rural early adolescent school girls in Dantan-II Block, Paschim Medinipur District, West Bengal. National Journal of Community Medicine. 2011;2,(1):14-8.

29. Alam N, Roy SK, Ahmed T, Ahmed AMS. Nutritional Status, Dietary Intake, and Relevant
Knowledge of Adolescent Girls in Rural Bangladesh. J. Health Popul. Nutr. 2010;28(1):8694.

30. Maliye CH, Deshmukh PR, Gupta SS, Kaur S, Mehendale AM, Garg BS. Nutrient Intake Amongst Rural Adolescent Girls of Wardha. Indian J. Community Med. 2010;35(3):400-2.

31. Bisai S, Bose K, Ghosh D, De K. Growth pattern and prevalence of underweight and stunting among rural adolescents. Nepal Paediatr. Soc. 2011;31:1724.

Cite this article as: Rahman S, Khan MH, Alam MM, Juneja K, Kumari S. A Population based study to assess the nutritional status of adolescents of Hajipur village of Katihar district, Bihar, India. Int J

Community Med Public Health 2016;3:270-5. 